\title{
Research on the Problems and Countermeasures of Archives Informatization Construction in Colleges and Universities
}

\author{
Liying Cui ${ }^{1, a}$, Li Ma ${ }^{2, b}$ \\ ${ }^{1}$ Jilin Agricultural University, Changchun, Jilin, China, 130118 \\ ${ }^{2}$ Changchun Architecture and Civilengeering College, Changchun, Jilin, China, 130118 \\ aemail,cuiliying07@126.com, bemail,794290328@qq.com
}

Keywords: Archives; Informatization Construction; Problems and Countermeasures; Reseach

\begin{abstract}
The construction of archives informatization is a main task of the university archives, and it is an important task of the university development, which promotes the process of the University's information construction. This paper expounds the importance of the construction of archival information; the need to increase infrastructure construction in the information construction. Put forward the requirement of the quality and service level of the staff in the file information construction. Analyze the problems encountered in the process of archives informatization, and put forward the countermeasures.Archives informatization construction is a basic work of University archives. The archives information construction is divided into three levels, the archives network construction, the construction of archives information resources, the development and utilization of archives resources. Comprehensively improve the level of file information, so as to improve the ability of file service. How to speed up the process of archives informatization in Colleges and universities is a subject that must be considered and studied by college and university archives management.
\end{abstract}

\section{The Importance of Strengthening the Construction of Archives Informatization in Colleges and Universities.}

Strengthening the construction of archives informatization is the inevitable choice and the objective requirement of the development of colleges and universities. The traditional file management mode cannot meet the needs of the information age, which requires the use of information technology to change the backward management mode. Colleges and universities in the development process has produced a large number of electronic documents, the existence of a variety of new file carriers for the management of the file workers has brought a challenge. To achieve effective management of electronic documents, to complete the digital form of storage and utilization, to realize the sharing of educational information resources, and to serve the development of college education, has become the focus of the archives work in Colleges and universities.

The Requirement of Information Age to File Management Information. Archives management needs to advance with the times, which is also the implementation of the National Archives on the National Archives of information construction and implementation of the program, the urgent need for. Traditional manual service oriented file management mode, cannot complete the collection and use of electronic archives, a serious lag of the real needs of archival information. Must change the backward management mode, in order to adapt to the development of the times, the archives information construction work is particularly important, to promote the steady development of archives is the inevitable condition is to strengthen the construction of archives informatization. The construction of archives information can solve the problems of the traditional space occupying, the difficulty of saving, the query is not convenient and so on. Make full use of the archives information resources, realize the archives management information, efficient and efficient archives information services to adapt to the development of the times.

The Construction of Archives Informatization in Colleges and Universities Is The Requirement of the Development of the School. A lot of text information and audio-visual materials, such as chart archives formation in the development of can be a true record of the 
development of school, is an important document in the development of the school, is a precious data measure of training quality, research level and development direction of talents in Colleges and universities, is the accumulation of experience, the improvement work, an important basis for the open field of vision, science planning, is based on the original series of historical research universities.

University archives information resource value has been paid more and more attention, in the important work of construction and development of colleges and universities, the connotation of its characteristic talents in Institutions of higher learning, training, assessment, and a school in the history of raw materials need to provide information and data file support. University leaders with access to these raw materials help to understand the specific situation, the development of School of scientific decision-making, help to deepen the reform of education and teaching, discipline construction and the professional development planning, and to cultivate talents for the society.

The Application of Information Technology Improves the Efficiency of Archives Work. The use of computer technology, paper documents and electronic files can be efficient and orderly filing the inevitable need for new management mode, the school responsibility department part-time archivists by sending and receiving files network, and will form in the process of the work file input or upload to the archives management system. The archives of professional archives management personnel will inspect the data entry system, receiving, file management system can automatic electronic archives archiving operation generation, each department part-time archivists share data entry work. This greatly reduces the workload of the archives management staff, greatly shorten the cycle of the formation of the file, and significantly improve the efficiency of the work.

\section{Problems Existing In the Construction of Archives Informatization in Colleges and Universities.}

Supporting Facilities Are Not Perfect Enough.Hardware construction is the premise and foundation of archival information construction. The file management system and many universities have not matched the computer will not be able to achieve the file information, and there is no scanner, antimagnetic cabinet large hinder archives informatization smoothly.

Software construction is also an important foundation for the construction of university information technology and security, although there is a lot of good hardware infrastructure. But not very good to play its due role, mainly in the software construction is not in place. Choose a stable, reliable, and at any time to upgrade and rest assured that the file management software is very important, you can speed up the process of file information, will greatly improve the efficiency of file services.

The Lack of Professional Talent Resources of Archives in Colleges and Universities. In the initial stage of archival information construction, manpower and material resources need a large amount of investment, and the original archives staff cannot meet the needs of the implementation of information technology. This is a serious obstacle to the archives of information technology, cannot grasp the archives of digital transformation technology is also to bring trouble to the construction of information technology.

On the one hand, the quality of the staff of the archives put forward requirements. File information construction is a huge project, the need to increase human and material resources; the quality of the staff is the key to the file. Archives staff is the core of the key, they decided to file management information level. On the other hand, the quality requirements of the file part time staff. To improve the comprehensive quality of the part time file clerk, and become a major problem in the construction of archival information. School information construction and the development of archives, the need for high-quality archives work team.

File Data Backup, Remote Backup and Other Security Problems. Many file departments in the file data backup, remote backup and other aspects of the existence of some security risks, unforeseen emergencies occur. We must ensure the security of archive data backup, otherwise, may cause a large amount of manpower, work not completed, all physical and experienced investment 
cast to waste. There is no sound mechanism for archives interlibrary, between different regions and different levels of archives off-site backup storage, lack of practical operability.

File backup, remote backup and other post management need to spend human and financial resources. Most file departments are not willing to do. In addition to the allocation of funds is limited, just to pay the file department daily supplies, it is difficult to bear the funds in remote backup.

Filing of Electronic Documents. Archives are the archives information service institutions, the collection of electronic documents, archiving and management is the focus of the work of archives. The development of office information, so that the school in the daily teaching, administrative, scientific research, construction and other work has produced a large number of electronic documents. The current lack of a unified electronic document archiving and management norms; electronic documents receiving, storage and use of the system also need to improve. Whether the preservation of electronic documents can be transformed into the corresponding transformation and how to ensure the authenticity of the electronic documents and the validity of the permanent security is a problem that must be solved.

\section{Analysis of the Archives Informatization Strategy Taking Jilin Agricultural University as an Example.}

The Establishment of Supporting Infrastructure Should Be Set up in the Construction of Archival Information. According to the actual situation of the archives to strengthen the construction of related software and hardware, in the existing equipment, based on the appropriate acquisition of the server and other hardware equipment. The application of the new instrument makes the management of archives information to a new level, and the work efficiency is greatly improved.

In order to speed up the modernization of archives management, the school introduced the "south big star" file management system software. This software set query, use in one, improve work efficiency, improve the management level, expand the foreign exchange, make the school archives information management work steadily. School has completed the directory level, part of the full text of the database entry upload work, make full use of good file management software is the necessary means to achieve the construction of archival information.

Establish a High Quality File Management Professional Team. Through the continuous introduction of professional talents, training of part-time staff to supplement the way of talent resources. For schools, the archives informatization is not a short period of time can reach a higher level, we start from the basis, conscientiously do a good job of planning of information construction, steadily promote the progress of the work, to promote the construction of archives informatization development.

The construction of archives informatization in Colleges and universities put forward new requirements on the quality of the staff, so that it can meet the needs of human resources, and promote the construction of archives informatization. Archives management personnel should change the way of thinking, innovative ideas, do a good job in the guidance of part-time staff, focusing on business training to explore new ideas.

High quality college file management personnel should have a strong sense of professionalism, a strong sense of responsibility, to have a wealth of professional knowledge of the archives and information technology knowledge. Jilin Agriculture University Archives cited recent file professionals, improve the education level and the degree of professional personnel, improve the ability of archives management personnel with professional knowledge to solve practical problems, pay attention to personnel archives work in the theoretical study and business exchanges and training. According to the actual situation of archival work, training for the various departments of the part-time file clerk, in order to ensure the efficiency and quality of archives work, the requirements of the various departments of the relative stability of the file.

The Solution to the Security Problems of File Data Backup and Remote Backup. Since the beginning of the description of the directory, the directory search query method brings great 
convenience to search for work, improve the efficiency and quality of service of archives. In the process of archives informatization construction, the data security of the file management software of the "south big star" is provided by the server and the remote backup method. To follow the "standard, practical, advanced" principle of the "south big star" software, it has data management, security, confidentiality, retrieval and system maintenance functions and other functions. To ensure data security, the software itself set every time automatic backup data must also complete manual data backup to the mobile hard disk, and then realize the remote backup, so be sure that no danger of anything going wrong data.

Solution to the Problem of Filing Electronic Documents. First, actively building various categories of archives database, provide fast and convenient service to users. The school has already built the teaching archives database, the scientific research achievement database and so on. Second, the creation of electronic document archiving management system. The archives staff of various departments make use of the file system software to catalogue, transfer to the archives information management network, and must ensure the universality and reliability of the file data. Again, improve the electronic filing system. Universities every year, a large number of data updates, the school departments to collect, identify, catalog, collate and archive materials, in accordance with the archives of archives management system to use the file management system to upload and transfer to the archives. Be sure to prevent information loss or illegal tampering, network environment, sharing and confidentiality, physical storage management and logical processing and other issues to strengthen attention. It must be the key point of the equipment safety and information security in the file information management.

Jilin Agricultural University is vigorously promoting the construction of archives information, archives information in their efforts to achieve at the same time, also in full consideration of digitalization construction of archives science, safety, feasibility and practical principle. The existing hierarchical digital library resources to promote, strictly on the basis of objective needs of digital construction, their financial and human resources investment.

\section{Conclusion}

In short, the era of big data, archives information construction is the new trend of the development of College Archives and inevitable choice, learn from the experience is bound to take some detours. The file information construction process there are some detours and mistakes need to correctly face the problems, cannot be divorced from reality, not in university learn from mistakes constantly sum up experience and learn the new way out of the construction of archives informatization has its own characteristics.

\section{References}

[1] L.S. Wang, The construction of archives informatization in Colleges and universities I see [J. Management and vertical and horizontal, 2011, 6, 32- 33.(In Chinese)

[2] Y.J. Liu, Thoughts on the construction of archives informatization in Colleges and universities [J. College of adult education, Hubei University, 2011.6. (In Chinese)

[3] Q.H. Yue, Wang Kezhong. Thoughts on the construction of archives informatization in Colleges and universities [J]. Modern marketing, 2013.3127-128. (In Chinese)

[4] F.L. Zhang,Thinking about the archives information construction of [J]. 2013, third chapters, 305. (In Chinese)

[5] C.X. Yu, Discussion on information construction of archives and archives service work [J. China management information, 2016 2: 176. (In Chinese)

[6] F. Yang, Research on the present situation and Countermeasures of the construction of archives informatization in Colleges and universities [J].Shanxi science and technology, thirtieth, fifth, 2015. (In Chinese) 
[7] X.M. Chen, In view of the problem of university archives information countermeasures [J]. Urban construction archives, 2016.04. (In Chinese)

[8] Z.H. Lang, University archives informatization construction of thinking and strategy [J]. Vocational Technology, 2016.08. (In Chinese)

[9] D. Chen, The archives information construction research [J]. Information and computer (theory), 13.2016. (In Chinese)

[10]Y. Zhao, The University archives informatization construction path [J]. Lantai World,20.2016 